\title{
Comparison of Morphologic Features and Mitotic Rate to Cytometrically Determined DNA Content of Poorly Differentiated Lymphocytic Lymphomas
}

\author{
MARGARITA PALUTKE, ${ }^{a}$ BERTRAM SCHNITZER, ${ }^{b}$ \\ DEBRA DRESNER,${ }^{a}$ PAMELA TABACZKA,${ }^{a}$ \\ VORAVIT RATANATHARATHORN, $c$ \\ LEOPOLDO EISENBERG, ${ }^{d}$ AND DAVID TENENBAUM ${ }^{a, e}$
}

\author{
${ }^{a}$ Department of Pathology \\ Section of Hematopathology \\ Berman Memorial Laboratories \\ Wayne State University School of Medicine \\ Detroit, Michigan 48201 \\ ${ }^{b}$ Department of Pathology \\ University of Michigan \\ Ann Arbor, Michigan 48104 \\ 'Department of Oncology \\ Wayne State University School of Medicine \\ Detroit, Michigan 48201 \\ ${ }^{d}$ Departments of Hematology and Oncology \\ Sinai Hospital \\ Detroit, Michigan 48235
}

\section{INTRODUCTION}

Several groups of investigators ${ }^{1-3}$ have demonstrated that DNA content analysis of lymphomas of low, intermediate, and high grade malignancy ${ }^{4,5}$ showed good correlation between $S$ phase values and aggressiveness of the lymphomas. There was considerable overlap of values, however, between intermediate and high grade lymphomas. As part of a larger study of more than 80 cases of poorly differentiated lymphocytic lymphomas (PDL) we were able to perform DNA histograms of 22 cases. Working within the Rappaport classification, ${ }^{6}$ we wanted to determined how morphologic criteria such as major cell type, number of

${ }^{e}$ No longer at Wayne State University School of Medicine; Present Affiliation: U.S. Army, Tank Automotive Command, Warren, MI 48397. 
transformed cells, blasts, and numbers of mitotic figures correlated with $\mathrm{S}$ phase values. For this we chose a group of poorly differentiated lymphocytic lymphomas of different morphologic subtypes.

\section{MATERIALS AND METHODS}

\section{Light Microscopic Studies}

The fresh cut surface of a lymph node was gently touched to clean microscope slides. These imprints were air dried and stained with Leishman's stain. Transverse sections of the lymph node (2-3 mm in thickness) were fixed in B5 fixative for routine histologic processing. Four to five micron sections were stained with hematoxylin-eosin (H\&E), periodic acid Schiff (PAS), and methyl green pyronin (MGP). For the present study special attention was paid to the growth pattern (nodular and/or diffuse), the morphologic characteristic of the major tumor cell population, the number of large transformed lymphocytes and blasts, and number of mitoses per high-power field. The latter was determined by counting mitoses in 10 high-power fields.

\section{Immunologic Studies}

The methods for preparing mononuclear cell suspensions and evaluation of surface immunoglobulin and other antigenic markers and receptors for unsensitized sheep red cells, complement (C), and immunoglobulin ( $\mathrm{Fc}$ ) have previously been described ${ }^{7-9}$ Cytocentrifuge preparations of all cell suspensions and the rosette tests were made using a Shandon-Elliot cytospin and were stained with Leishman's stain.

\section{DNA Analysis}

In all cases DNA histogram analysis was performed using cells obtained from teased lymphoid tissue and peripheral blood Ficoll-Hypaque monolayers. All cells were fixed in $70 \%$ ethanol prior to testing. Chicken erythrocyte nuclei were used as an external standard for the histograms. The nuclei were prepared by washing the whole chicken cells with $\mathrm{CaCl}_{2}(0.332 \mathrm{~g} / \mathrm{L}$ saline $)$ and lysing the cell membrane with saponin $(50 \mathrm{mg} / 100 \mathrm{ml}$ saline $)$. Free nuclei were then rewashed with $\mathrm{CaCl}_{2}$ and fixed in $70 \%$ ethanol until ready to use. Sample cell concentrations were adjusted to $4 \times 10^{6}$ cells $/ \mathrm{ml}$ to which $1.2 \times 10^{5}$ cells $/ \mathrm{ml}$ of the chicken erythrocyte nuclei were added. ${ }^{1}$ Treatment with $\mathrm{RNase}(1 \mathrm{mg} / \mathrm{ml})$ at $37^{\circ} \mathrm{C}$ for 30 minutes followed to eliminate double-stranded RNA. The nuclear DNA was stained with propidium iodide $(5 \mathrm{mg} / 100 \mathrm{ml})$ in $0.1 \%$ sodium citrate at $4^{\circ} \mathrm{C}$ for 20 minutes. ${ }^{10}$ Prior to analysis, each sample was filtered through a $37 \mu \mathrm{m}$ nylon mesh to remove cellular debris then sonicated to minimize clumping.

Analysis on 12 cases was performed on a 128 channel Coulter TPS-1 flow cytometer using the $388 \mathrm{~nm}$ line of a $5 \mathrm{~W}$ argon ion laser at $500 \mathrm{~mW}$ constant light output for fluorescent excitation. A $590 \mathrm{~nm}$ long pass dichroic filter was placed in front of the red photomultiplier tube to allow the passage of red fluorescent 
商

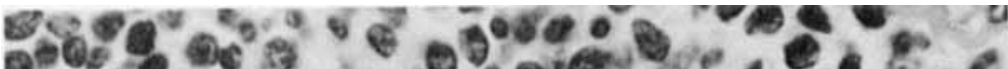

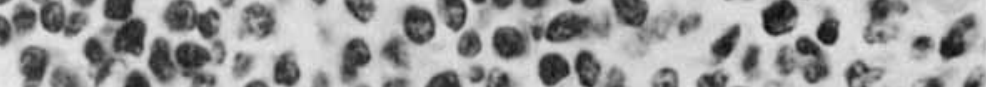

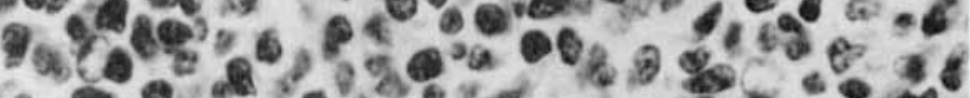

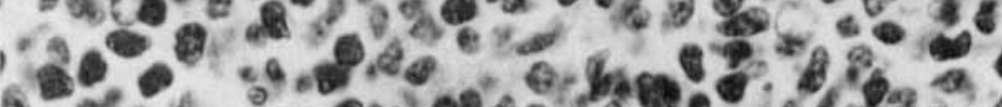

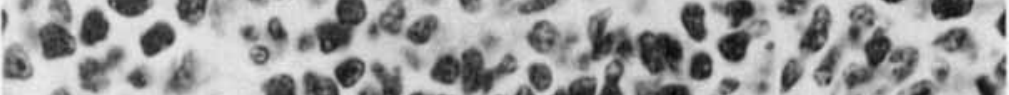

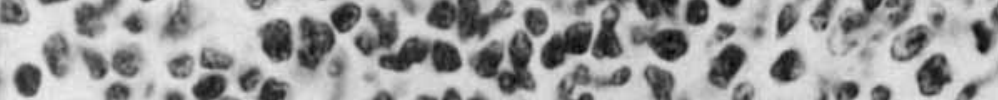

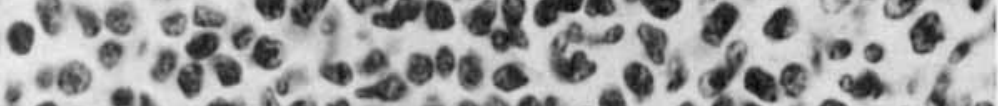

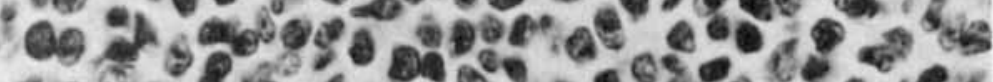

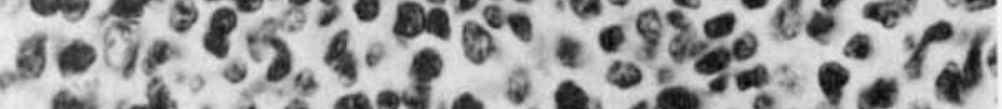

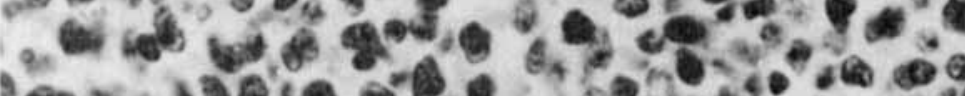

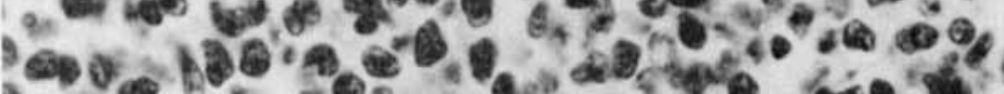

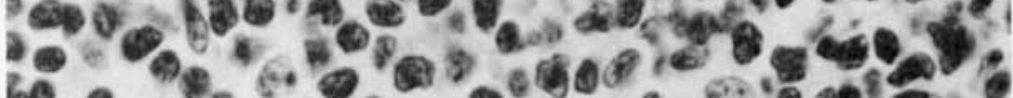





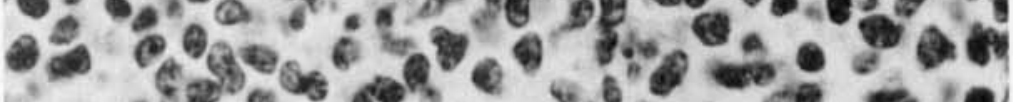
- is Q⿻

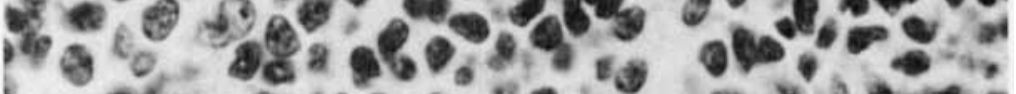

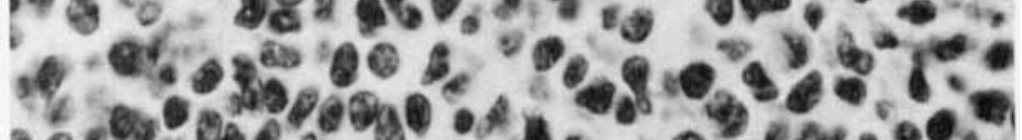

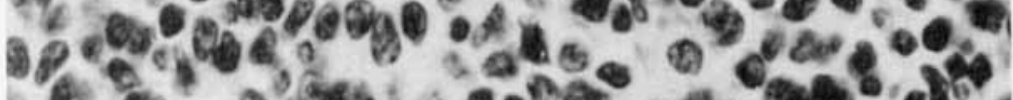

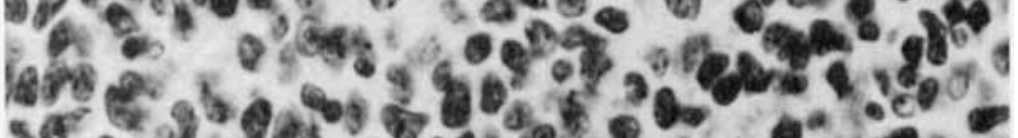

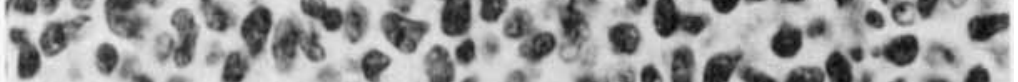

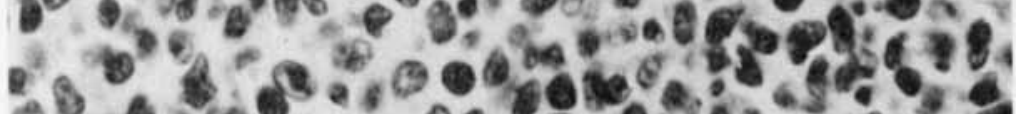

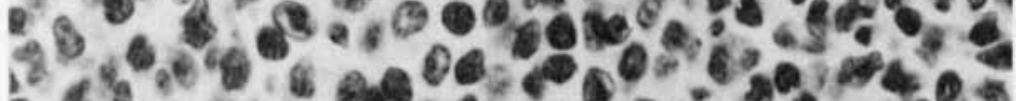



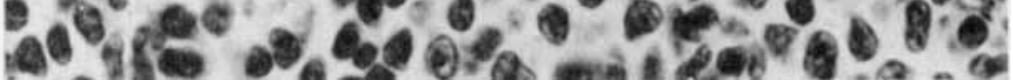

递

है

这

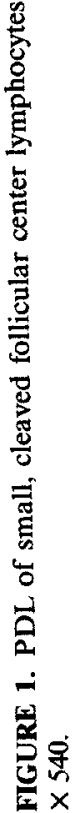


emissions for the DNA measurements. Data were analyzed on an Amdahl 470V/6 and $470 \mathrm{~V} / 8$ computer using the DNA histogram program kindly supplied by Dr. Philip Dean of Livermore Laboratories in California."

Analysis on 10 cases was performed on a 256 channel FACS 440 (Becton Dickinson, Sunnyvale, CA) flow cytometry system using $100 \mathrm{nW}$ of constant light output from the same laser. A $488 \mathrm{~nm}$ blocking and $575 / 25 \mathrm{~nm}$ narrow band pass filter system was placed in front of the red photomultiplier tube to detect the emissions. Data analysis was performed on a PDP-11/23 microcomputer Consort 40 (Becton Dickinson, Sunnyvale, CA) using a similar program also supplied by Dr. Philip Dean.

\section{RESULTS}

\section{Light Microscopic Findings}

The 22 cases were divided into three histological groups: (1) nodular PDL composed predominantly of small, cleaved lymphocytes ${ }^{12}$ (11 cases); (2) follicular mantle zone lymphoma and those of intermediate differentiation ${ }^{13-15}$ (6 cases); and (3) "blastic" PDL ( 5 cases) in which blasts were more numerous than cleaved lymphocytes. ${ }^{16}$ Mitoses in Group 1 ranged from 0.1 (Fig. 1) to 5.7/HPF (FIG. 2) (mean $=2.5 / \mathrm{HPF}$ ) and the percentage of large cells or blasts correlated well with the number of mitoses (TABLE 1). In Group 2 the number of mitoses was low in five cases: $0.2-1.1 / \mathrm{HPF}$ (mean $=0.7 / \mathrm{HPF}$ ), but the percentage of large cells was high because these cells were present in remnants of normal follicle centers and in malignant pseudo-follicular proliferation centers (FIG. 3). Case 17 in this group differed from the other five cases in that both the mitotic rate $(4.8 / \mathrm{HPF})$ and the percentage of cells in $\mathrm{S}$ phase $(10 \%)$ were considerably higher. Cytologic examination of the lymph node (FIG. 4) and blood revealed many prolymphocytes in addition to the usual mixture of round and small cleaved lymphocytes, characteristic of this type of lymphoma. Mitoses were seen predominantly in cells of the same size as the prolymphocytes rather than in large cells. In Group 3, blasts predominated although a minor cell population consisted of cleaved lymphocytes (FIG. 5). This group had the highest mitotic rate $(4.5-8.8 / \mathrm{HPF}$; Mean $=6.1 / \mathrm{HPF}$ ).

\section{Immunologic Findings}

As seen in TABLE 1, all the cases were of B-cell type. The percentage of T cells varied from 7 to 37 percent. They were considered a nonneoplastic component of the lymphoid tissue and their numbers did not appear to influence the size of the $\mathrm{S}$ phase compartment.

\section{Cell Cycle Analysis}

The correlation of the percentage of cells in the $S$ phase of the cell cycle and number of mitoses and types of tumor cells are given in TABLE 1. Control values are given in TABLE 2. A DNA histogram of a lymph node with benign reactive follicular hyperplasia is seen in FigURE 6. 




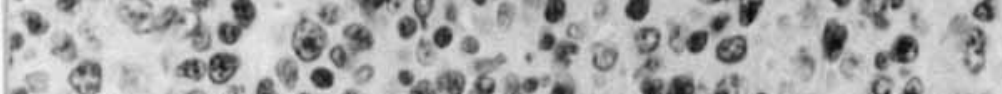

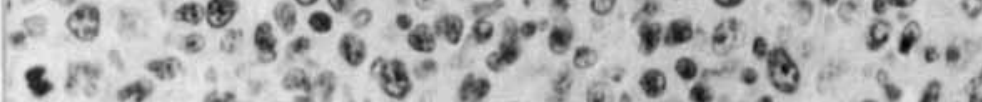



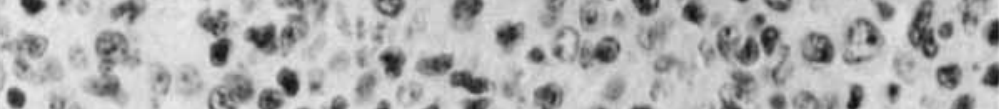
- 9

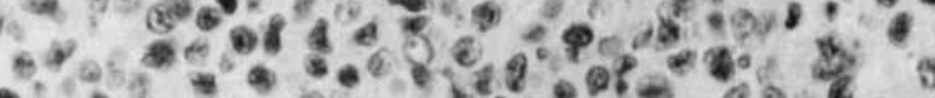

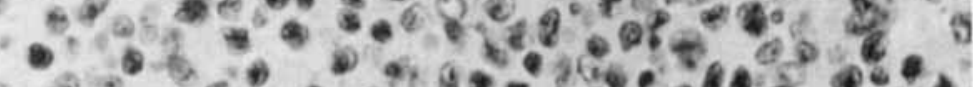

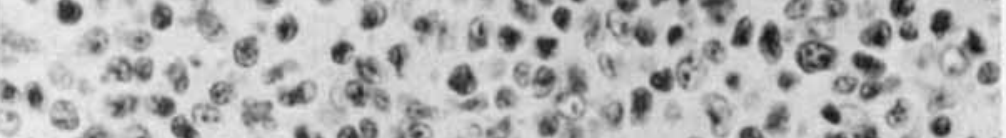



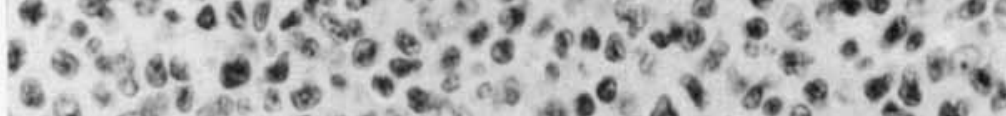

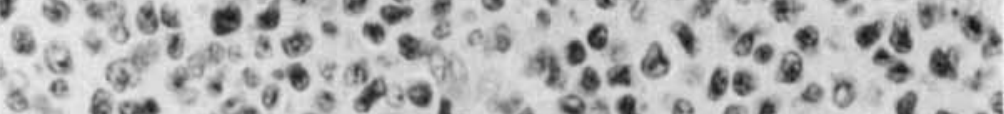

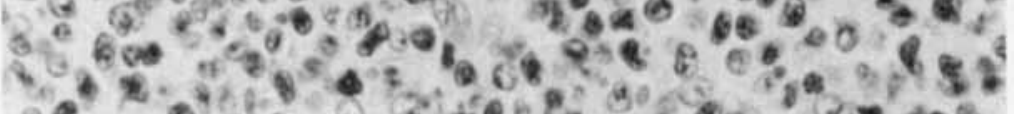

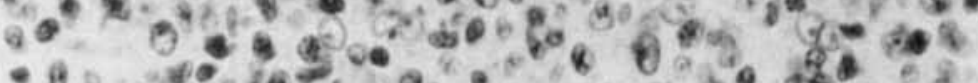



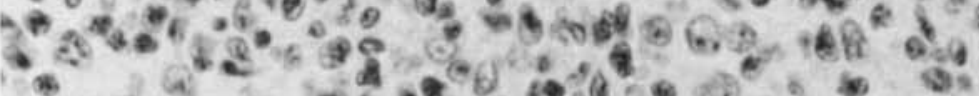

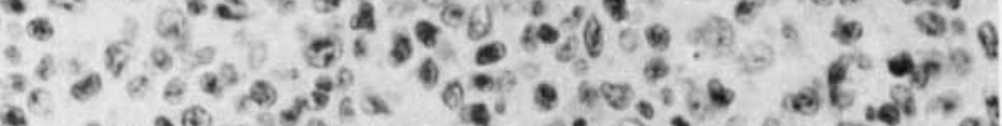

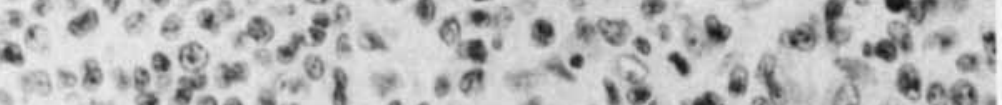

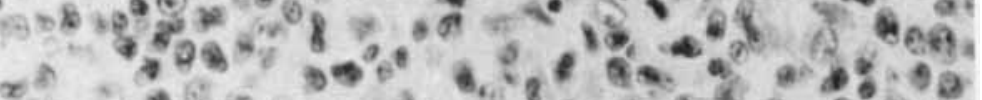

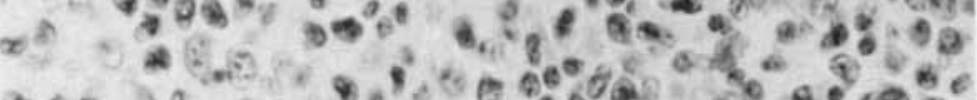

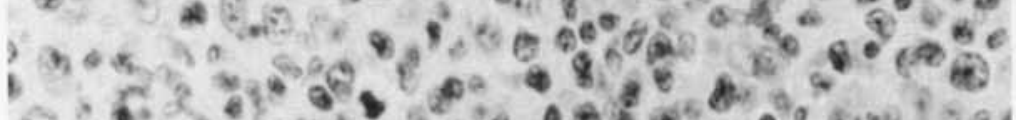

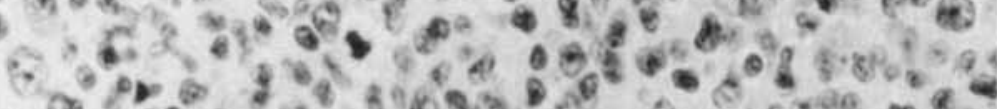

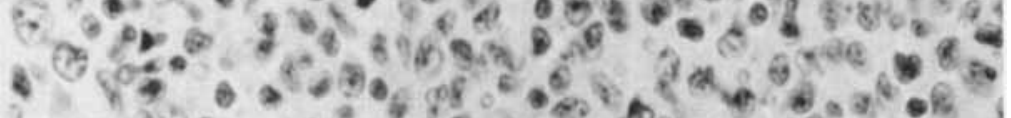

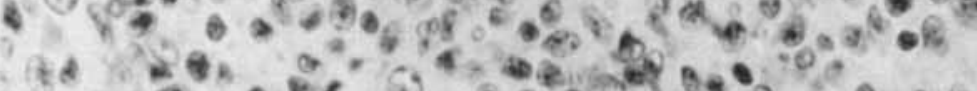

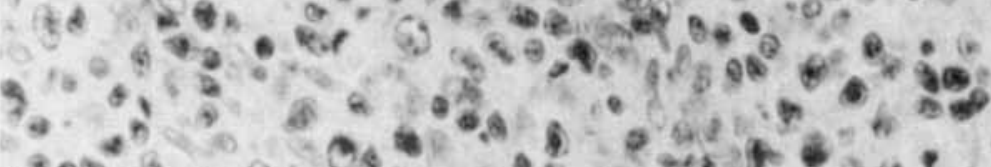



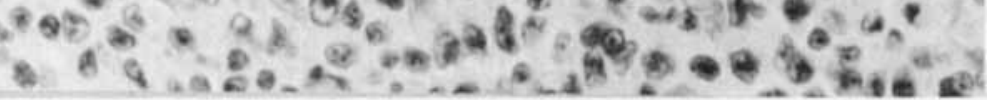




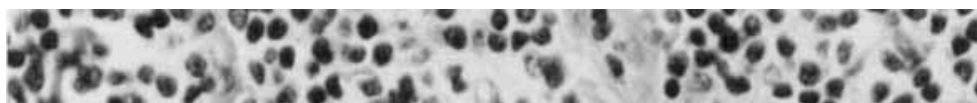

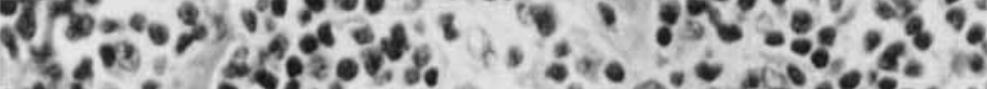

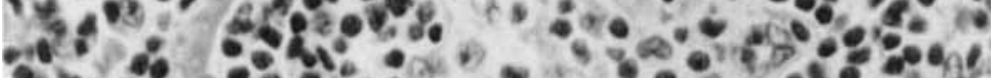

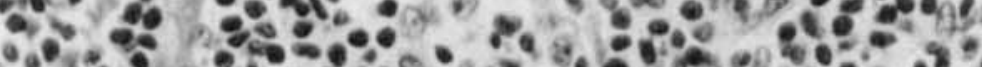

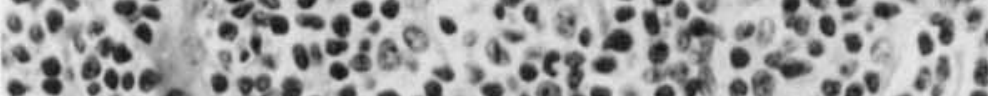
-

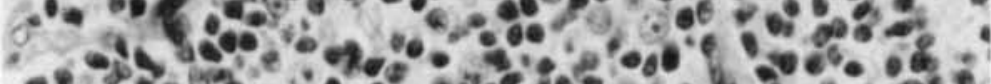
-

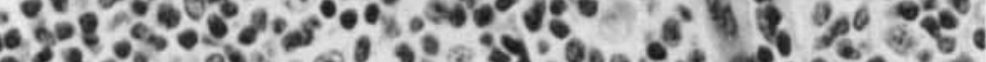

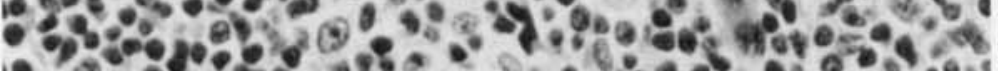

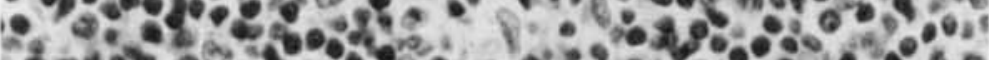

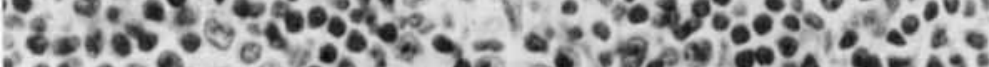

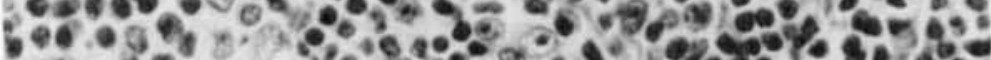
4.

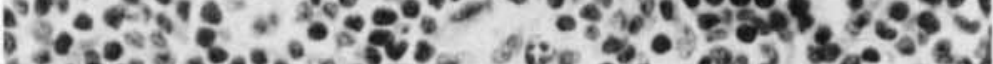



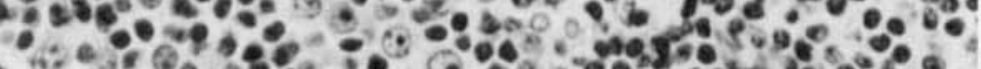

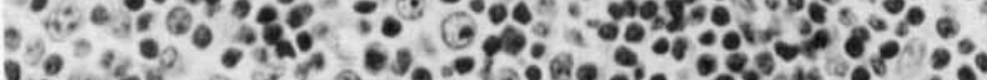

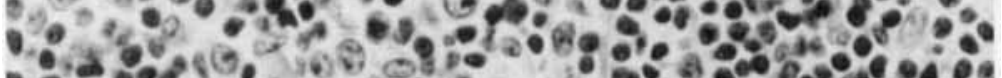

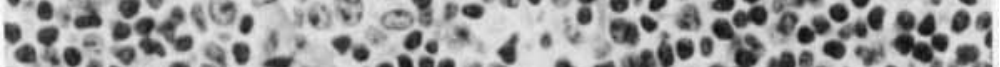
ayo

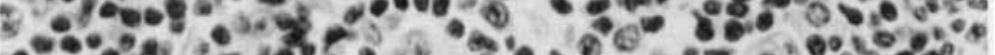

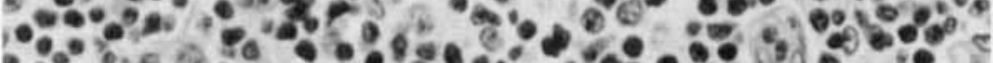




$60.80,80,4$ P

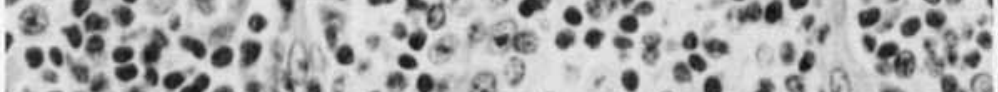

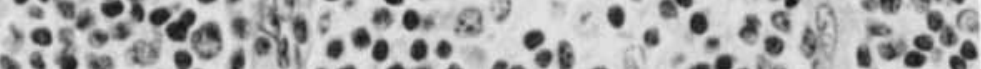

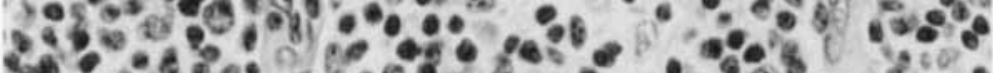
b.

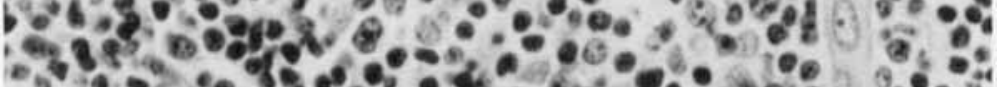
i. C.9.

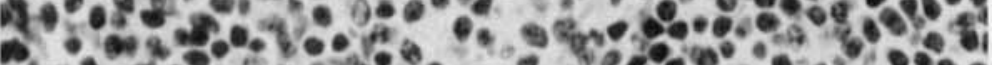

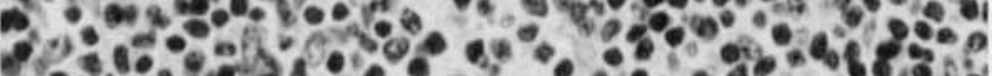

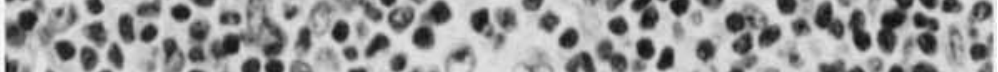

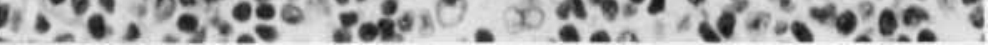




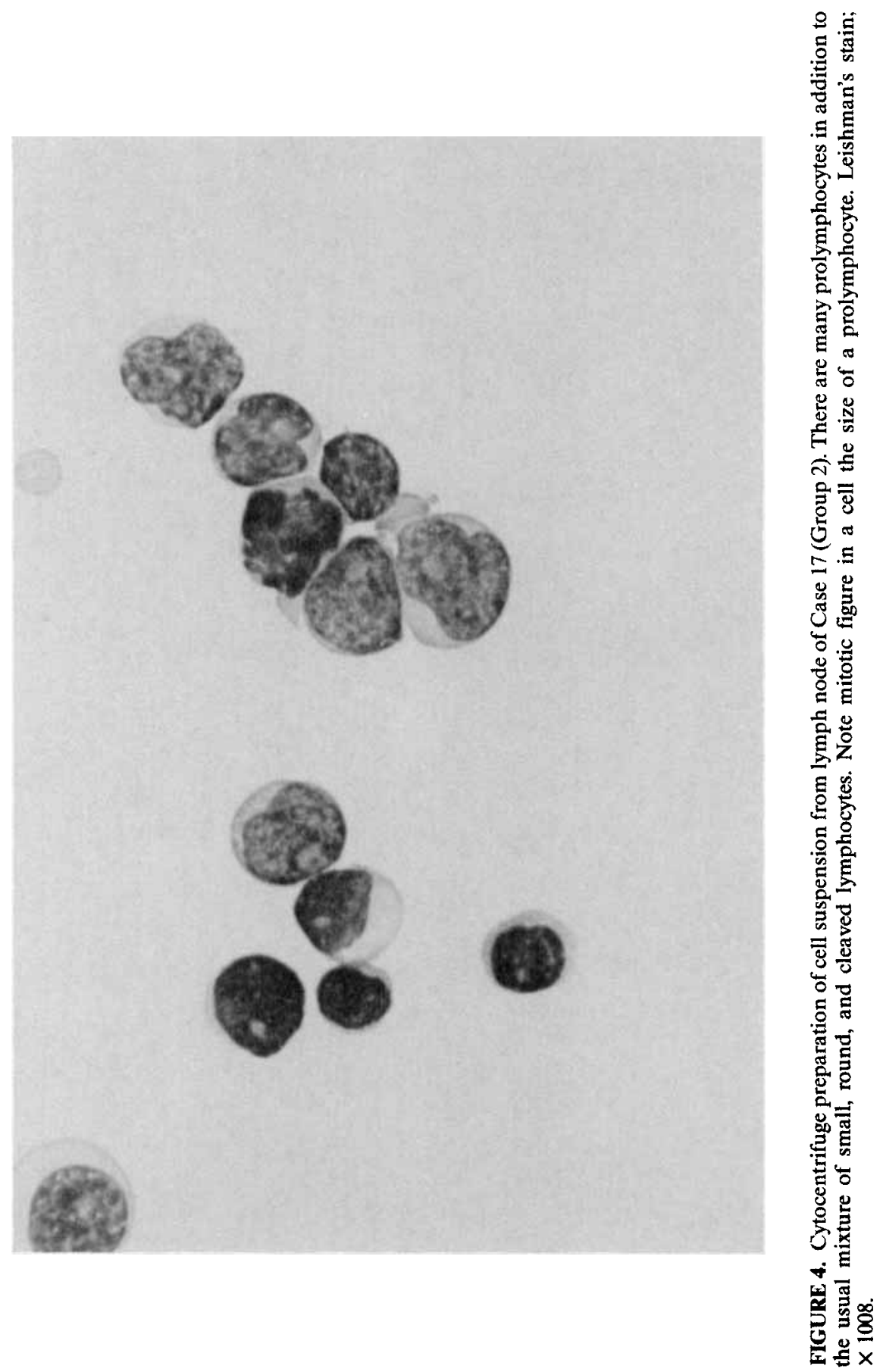




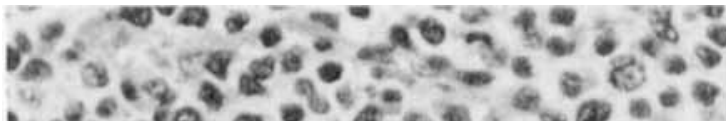

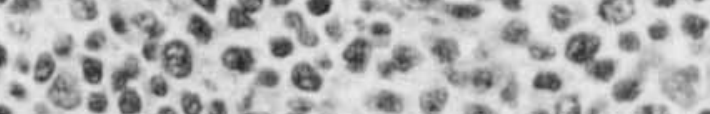





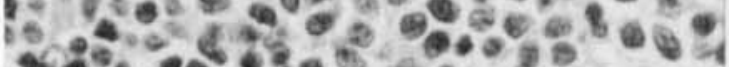

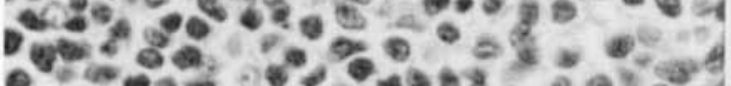

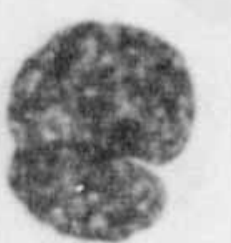





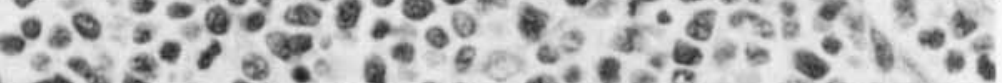

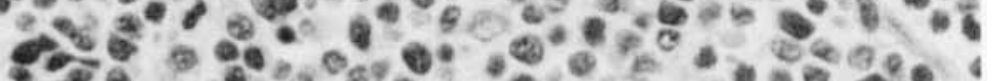

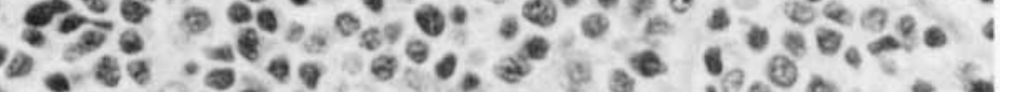

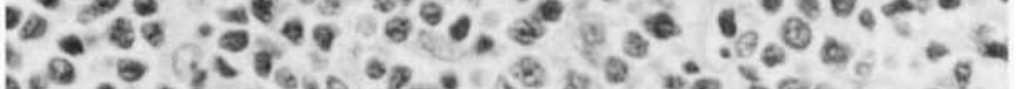

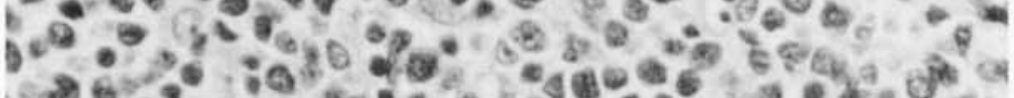

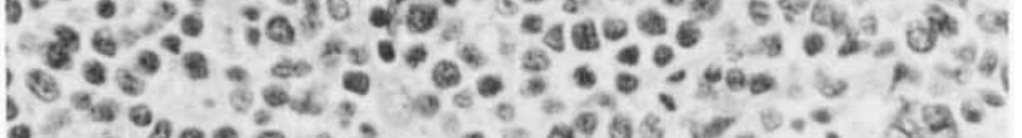



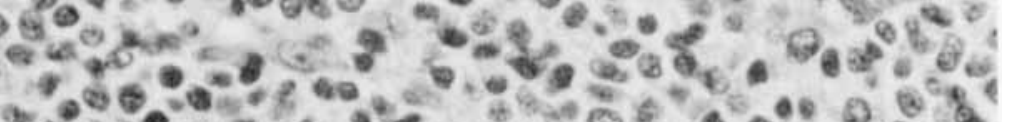



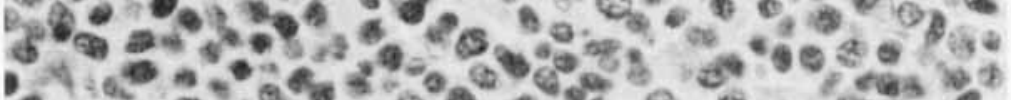

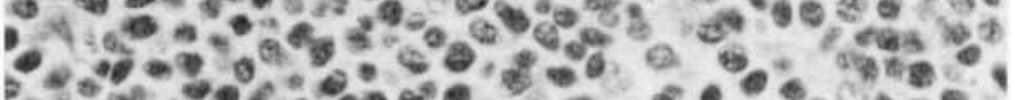

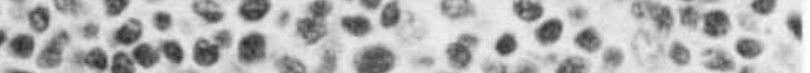

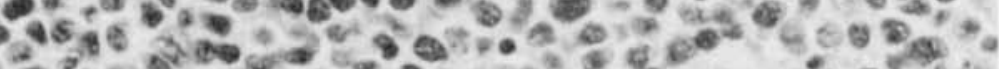

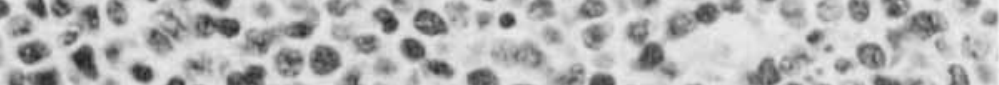

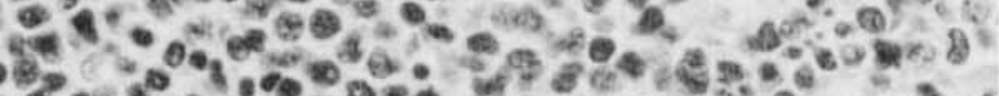

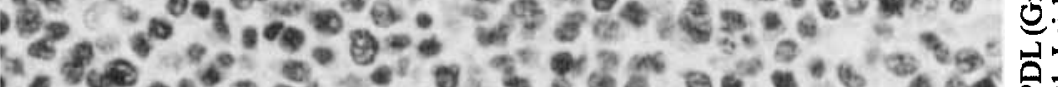

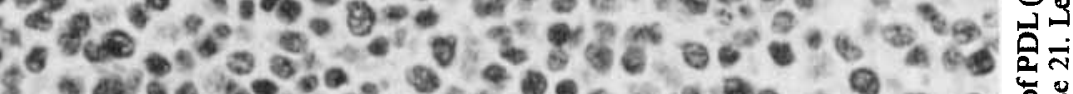

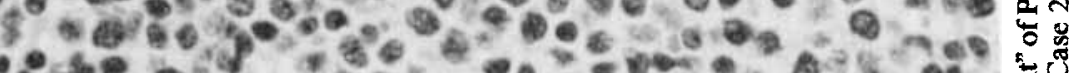

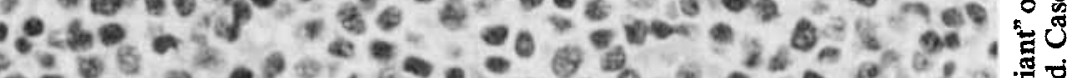

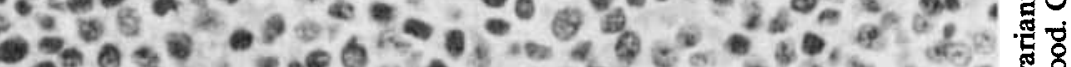

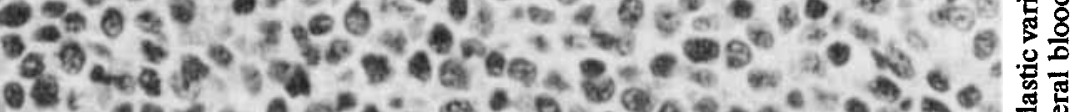

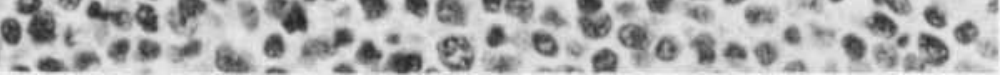
案 욜 min (1) 
TABLE 1. Correlation of Histologic Criteria and Cell Cycle Analysis

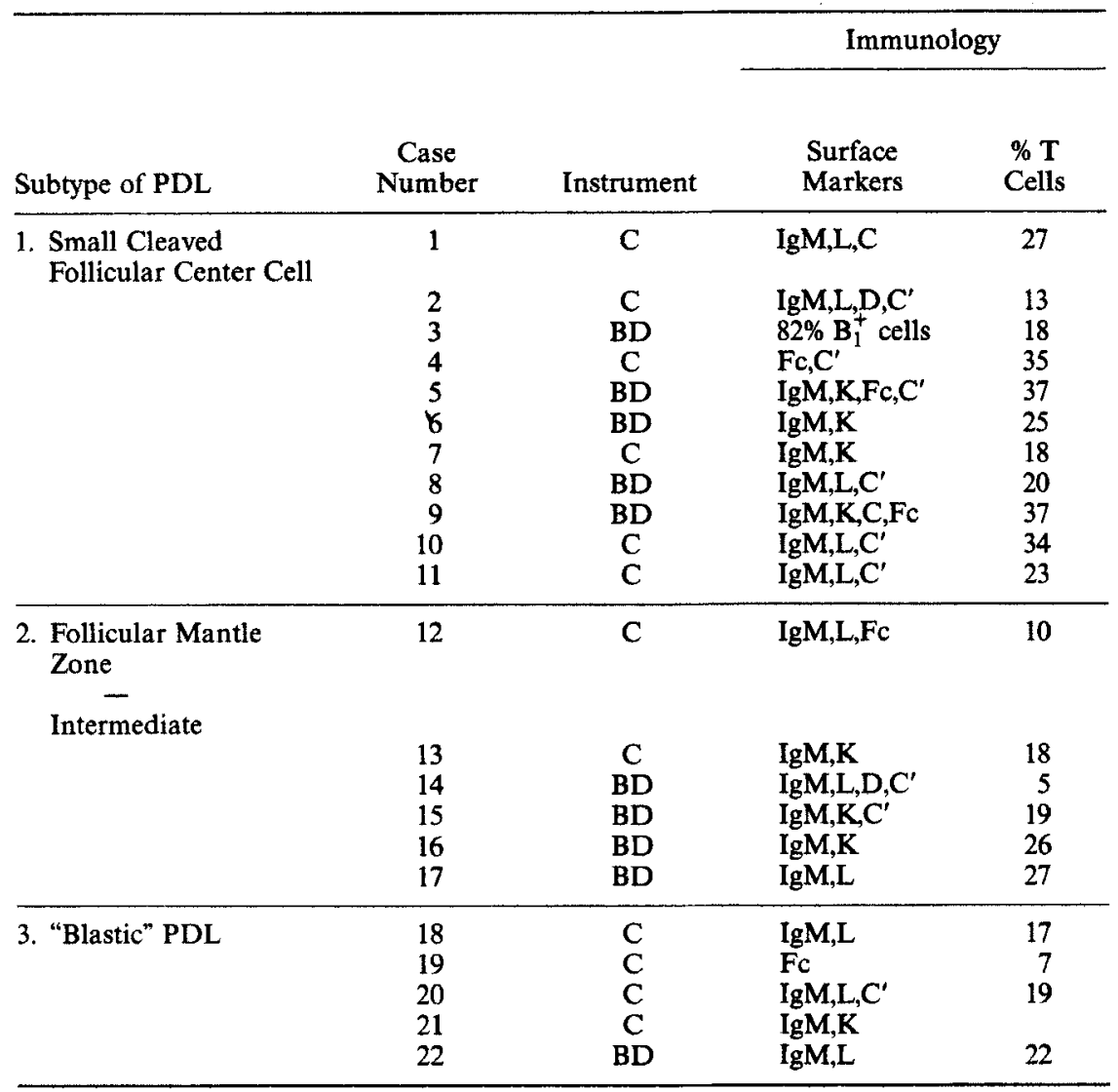

In Group 1 there was excellent correlation between percentage of large cells or blasts, number of mitoses and percentage of cells in $\mathrm{S}$ phase $(1.0-5.0 \%$; Mean $=2.5 \%)($ Fig. 7$)$. In Group 2 the percentage of cells in S phase $(3.2-6.0 \%$; Mean $=4.4 \%$ ) correlated with the size of the large cell component but not with number of mitoses except for one case (case 17) (FIG. 8). In Group 3 there was a better correlation of the $\mathrm{S}$ phase $(9.7-22.3 \%$; Mean $=16 \%)$ with the number of blasts than with the number of mitoses (Fig. 9).

Cases 19 and 22 showed two $G_{0} / G_{1}$ peaks (Flgs. 10 and 11) representing aneuploidy. The coefficient of variation (CV) of several other cases in all three groups was unusually high and could be a result of aneuploidy.

\section{DISCUSSION}

A correlation between the percentage of cells in the $\mathrm{S}$ phase of the cell cycle and clinical behavior of lymphocytic lymphomas of low, intermediate, and high grade 


\begin{tabular}{|c|c|c|c|c|c|c|c|c|}
\hline \multicolumn{5}{|c|}{ Histologic Criteria } & \multicolumn{4}{|c|}{ DNA Analysis } \\
\hline Nodular & Diffuse & $\begin{array}{l}\text { Large } \\
\text { Cells } \\
(\%)\end{array}$ & $\begin{array}{c}\% \\
\text { Blasts } \\
(\%)\end{array}$ & $\begin{array}{l}\text { Mitoses } \\
\text { / High } \\
\text { Field }\end{array}$ & $\begin{array}{c}\text { Cells } \\
\text { in } \mathrm{G}_{0} \mathrm{G}_{1} \\
\text { Phase } \\
(\%)\end{array}$ & $\begin{array}{c}\text { Cells } \\
\text { in S } \\
\text { Phase } \\
(\%)\end{array}$ & $\begin{array}{l}\text { DNA } \\
\text { Ratio }\end{array}$ & $\mathrm{CV}$ \\
\hline $\mathrm{X}$ & & $<10$ & & 0.1 & 97.9 & 1.5 & 4.26 & 4.45 \\
\hline$X$ & & $<10$ & & 0.3 & 97.3 & 1.4 & & 5.76 \\
\hline $\mathrm{X}$ & & $<10$ & & 0.6 & 96.5 & 2.2 & 2.82 & 3.70 \\
\hline $\mathrm{X}$ & & $<10$ & & 1.6 & 97.4 & 1.6 & & 3.33 \\
\hline$X$ & & $10-20$ & & 1.7 & 95.0 & 2.0 & 4.10 & 3.90 \\
\hline$X$ & & $10-20$ & & 1.7 & 96.0 & 1.0 & 2.65 & 3.20 \\
\hline$X$ & & $<10$ & & 2.2 & 95.9 & 3.3 & 2.70 & 3.44 \\
\hline $\mathrm{X}$ & $\mathrm{X}$ & $10-20$ & & 3.0 & 95.0 & 3.0 & 2.74 & 3.90 \\
\hline $\mathrm{X}$ & & $20-30$ & & 4.7 & 90.0 & 5.0 & 3.33 & 3.90 \\
\hline $\mathrm{X}$ & $\mathrm{X}$ & $<10$ & $10-20$ & 5.6 & 97.0 & 4.5 & 3.00 & 5.73 \\
\hline $\mathrm{X}$ & $\mathrm{X}$ & $10-20$ & 10 & 5.7 & 95.3 & 4.7 & 3.07 & 5.15 \\
\hline $\mathrm{x}$ & & $20-30$ & & 0.7 & 92.4 & 4.9 & 3.00 & 5.04 \\
\hline faintly & $\mathrm{X}$ & $20-30$ & & 0.2 & 97.1 & 3.2 & 3.14 & 3.53 \\
\hline faintly & $\mathrm{X}$ & $20-30$ & & 0.7 & 88.9 & 4.4 & 2.94 & 3.70 \\
\hline faintly & $\mathrm{X}$ & $10-20$ & & 1.1 & 90.0 & 6.0 & 2.71 & 3.80 \\
\hline faintly & $\mathrm{X}$ & $20-30$ & & 0.9 & 93.0 & 3.4 & 2.50 & 3.86 \\
\hline faintly & $\mathrm{X}$ & $10-20^{a}$ & & 4.8 & 90.0 & 10.0 & 2.38 & 5.60 \\
\hline & $\mathrm{X}$ & & pred & 6.5 & 90.0 & 9.7 & 2.79 & 5.15 \\
\hline $\mathbf{X}$ & $\mathrm{X}$ & & pred & 5.7 & 84.6 & $\mathrm{NC}^{b}$ & $\mathrm{NC}$ & $\mathrm{NC}$ \\
\hline $\mathrm{X}$ & & & pred & 8.8 & 84.4 & 15.6 & & 7.72 \\
\hline$x$ & $X$ & & pred & 5.1 & 71.1 & 22.3 & 2.90 & $5.63^{c}$ \\
\hline$X$ & $\mathrm{X}$ & $<10$ & $>50$ & 4.5 & NC & $\mathrm{NC}^{b}$ & NC & $\mathrm{NC}$ \\
\hline
\end{tabular}

${ }^{a}$ Many prolymphocytes. ${ }^{b}$ Not calculated owing to aneuploidy.

${ }^{c}$ Done on blood.

malignancies has been described. ${ }^{1-3}$ The study by Diamond et al. ${ }^{1}$ demonstrated that the range of $S$ phase values is quite broad in the intermediate $(4.9-21.5 \%)$ and high grade $(15.4-31.5 \%)$ groups.

Our study of 22 cases of poorly differentiated lymphocytic lymphomas, including six cases of lymphocytic lymphoma of intermediate differentiation, was aimed at determining whether histologic features had any direct correlation to the percentage of cells in $\mathbf{S}$ phase.

The 22 cases were divided into three groups: (1) small, cleaved follicular center cell lymphomas; ${ }^{12}(2)$ mantle zone lymphomas and lymphomas of intermediate differentiation; ${ }^{13-15}$ and (3) "blastic" type. ${ }^{16}$

In Group 1 there was a good correlation between the mitotic rate $(.1-5.7 \%$; Mean $=2.5 \%$ ), the number of large, transformed round cells and/or blasts $(<10-30 \%)$, and the percentage of cells in $S$ phase $(1.0-5.0$; Mean $=2.5 \%)$. 


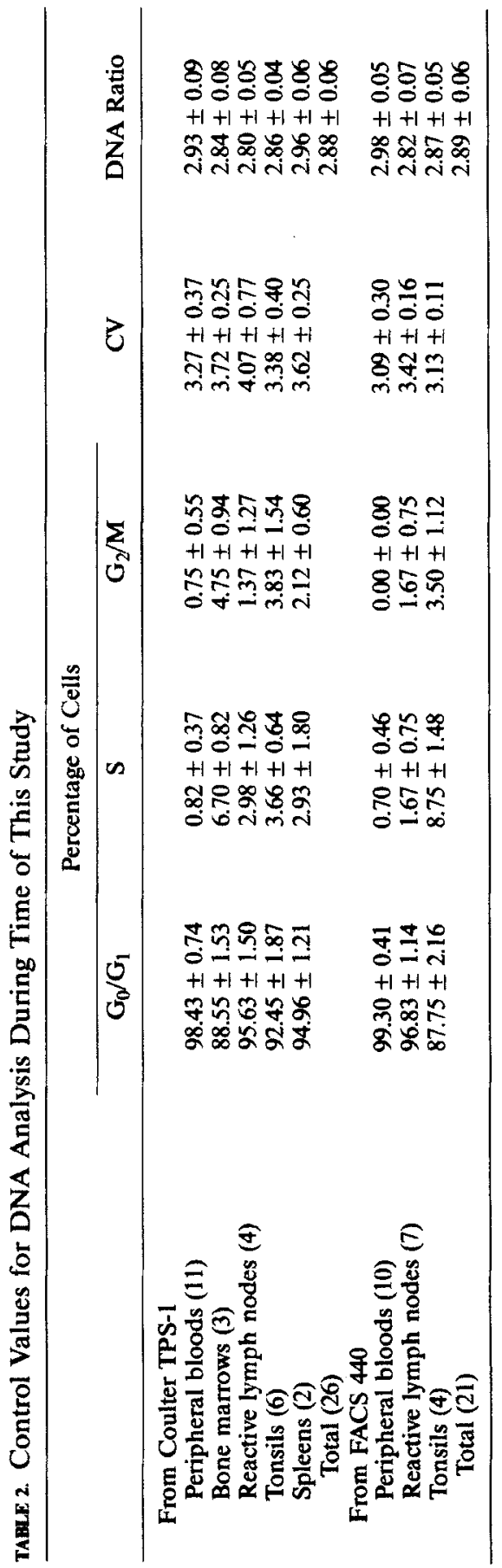




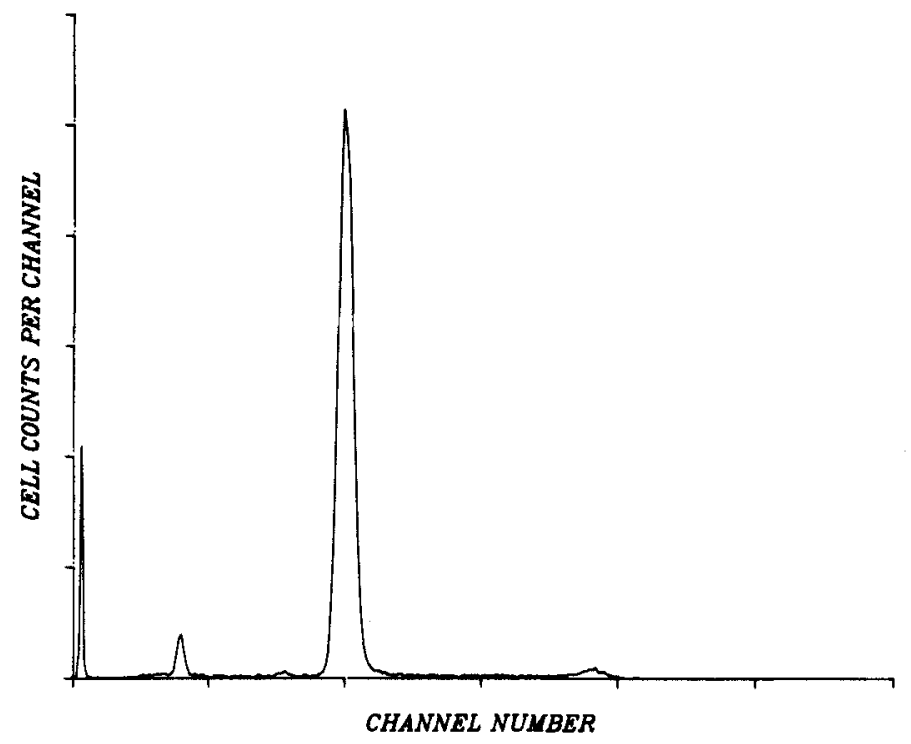

FIGURE 6. DNA histogram of lymph node showing benign follicular hyperplasia.

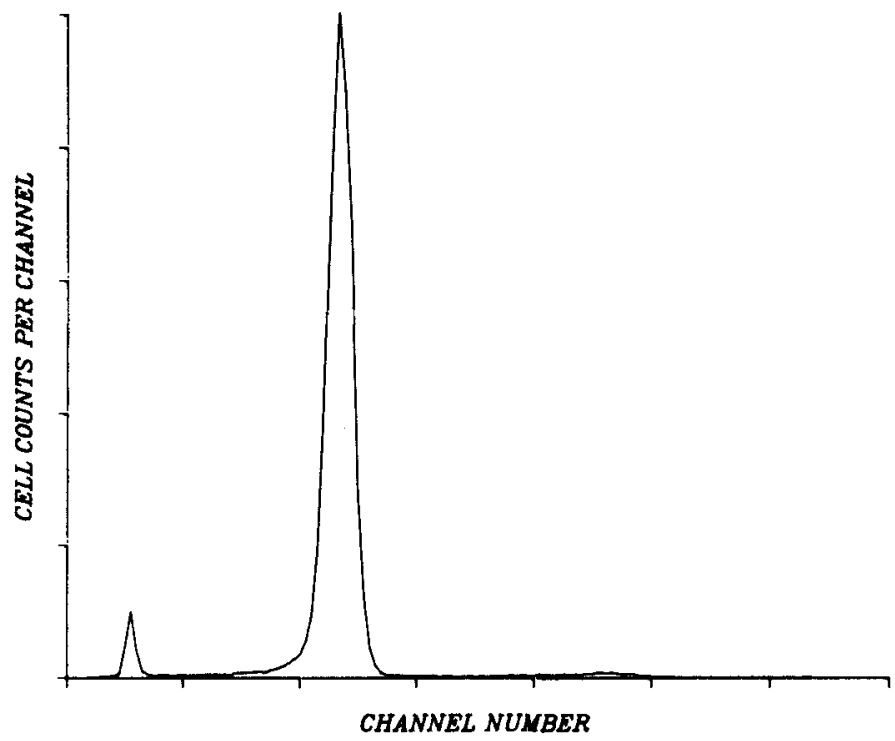

FIGURE 7. DNA histogram of PDL from Group 1 with small percentage of cells in S phase, $1.5 \%$. 




FIGURE 8. DNA histogram of lymphoma of intermediate differentiation with unusually high S phase (10\%), Case 17.



FIGURE 9. DNA histogram of "blastic" variant (Group 3). Case 21. S phase $=22.3 \%$. 




FIGURE 10. DNA histogram of "blastic" variant (Group 3). Case 19. Two distinct $G_{0} / G_{1}$ peaks are noted. $S$ phase is also high, but was not calculated.

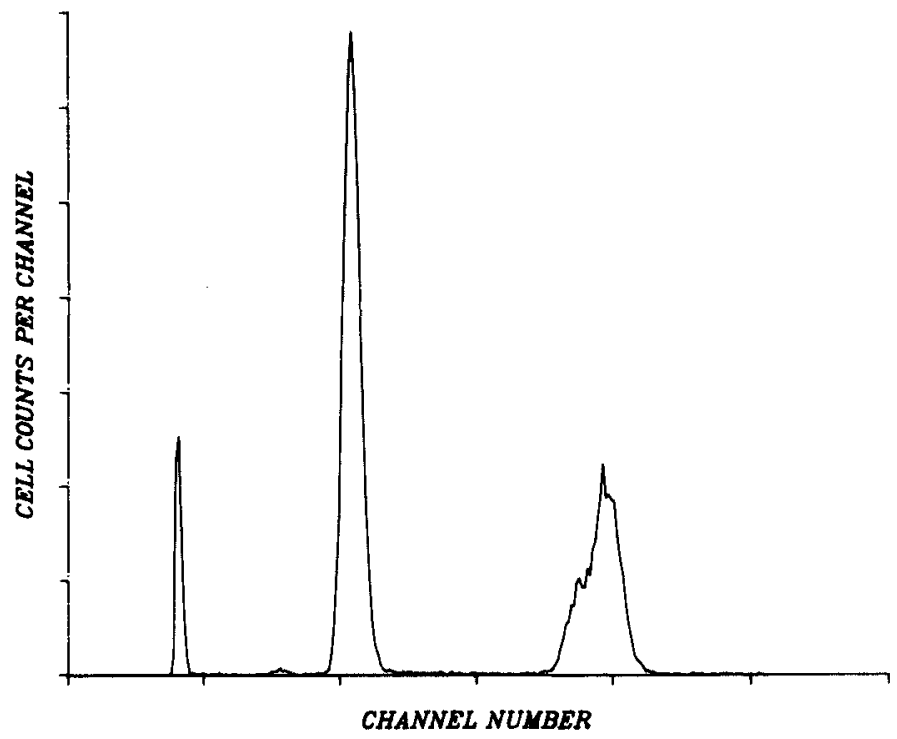

FIGURE 11. DNA histogram of "blastic" variant (Group 3). Case 22. Most of the tumor cells are near tetraploid. Normal $\mathrm{T}$ cells are $22 \%$ in this case and are presumed to be part of the diploid $G_{0} / G_{1}$ population. 
Lymphomas of intermediate differentiation and their variant, mantle zone lymphoma (Group 2) are characterized by a mixture of small cleaved and mature small round lymphocytes and pseudofollicular proliferation centers composed of large, transformed lymphocytes and remnants of normal follicular centers which also contain large, transformed lymphocytes. There was no correlation between mitotic rate $(0.2-1.1 \%$; Mean $=0.7 \%)$ and the $\mathrm{S}$ phase component $(3.24-6.0 \%$; Mean $=4.4 \%$ ). The high $S$ phase component may be due to a large number of large transformed cells, which may have a prolonged $S$ phase. In one of these cases placed in this group, Case 17 , the number of mitoses $(4.8 / \mathrm{HPF})$ was considerably higher than in the other five and the percentage of cells in $\mathrm{S}$ phase (10\%) was also higher. In this case a large number of partially transformed nucleolated cells, prolymphocytes, were noted and mitoses were present in cells of similar size. This case probably represents an accelerated phase of this type of lymphoma.

In Group 3 the "blastic" PDLs had high mitotic rates $(4.5-8.8 / \mathrm{HPF}$; Mean $=6.1 / \mathrm{HPF})$ and high $\mathrm{S}$ phases $(9.7-22.3 \%$; Mean $=16 \%)$. Compared to Group 1, the $S$ phase component was considerably higher relative to the mitotic rate and more consistent with the number of blasts in the lesion. The two cases of distinct aneuploidy also occurred in this group. This group of lymphomas was considered to have arisen from follicular center cells as evidenced by the presence of small, cleaved cells and nodular growth patterns in four of the five cases. Nodular PDL of small, cleaved follicular center cell type (Group 1) may undergo transformation into lymphomas consisting of large transformed lymphocytes or blasts. $^{16}$ These blasts, because of their small size, may be more difficult to distinguish from the cleaved lymphocytes than are large transformed cells and thus a transformation of a nodular PDL to a more aggressive lymphoma may be undetected by the pathologist. Some of the PDLs may be this variant at initial presentation. Three of the five patients in the "blastic" group died within two years. The other two have had a much more aggressive course than the patients in the other two groups.

In summary, in nodular PDLs composed of small cleaved lymphocytes and in "blastic" PDLs there appears to be a correlation between mitotic rate and the number of blasts or large transformed lymphocytes. This does not appear to be the case in lymphomas of intermediate differentiation where relatively high $\mathbf{S}$ values do not correspond to the mitotic rate but may reflect the presence of large transformed cells. This group of cases, however, is quite small and further studies are needed. Nodular PDL is considered a lymphoma of low grade malignancy. It is important to recognize "blastic" transformation or a "blastic" variant of PDL. Because the prognosis of patients with this form of PDL is considerably worse, ${ }^{16}$ they should be considered to lymphomas of intermediate or high grade malignancy. 45

\section{SUMMARY}

A direct correlation between the percentage of cells in $S$ phase of the cell cycle and the clinical behavior of lymphocytic lymphomas of low, intermediate, and high grade malignancy has been described. The histopathologist has used the mitotic rate and other morphologic criteria such as size of cells and nuclear characteristics as predictors/indicators of the aggressiveness of a tumor. We compared the $S$ phase values of 22 cases of poorly differentiated lymphocytic 
lymphoma (PDL) of the B cell type, using flow cytometric measurement of DNA content, to morphologic features and mitotic rate (MR). The 22 cases were divided into 3 histologic groups: (1) nodular PDL composed of small, cleaved lymphocytes ( 11 cases); (2) follicular mantle zone lymphoma and those of intermediate differentiation (6 cases); and (3) "blastic" PDL ( 5 cases). In Group 1 there was excellent correlation of MR, percentage of cells in S phase, and proportion of large cells (transformed lymphocytes) per high power field (HPF). In Group 2, this correlation was not found between MR and percentage of cells in S phase in five of the six cases. The high $\mathrm{S}$ phase in this group did correlate with the large proportion of large cells found primarily in pseudofollicular proliferation centers and in remnants of true follicular centers. These cells may have a prolonged $S$ phase and thus fewer mitoses were seen. In Group 3, although both MR and S phases were high, a direct correlation between them as noted in the Group 1 cases was not seen, but an excellent correlation of the high $S$ phase and the number of blasts was present. The fact that three of the five patients in this group died rapidly (within less than 2 years of presentation) and the two survivors were experiencing rapid progression of disease, supports the concept that this group represents a clearly different, more aggressive subclass of PDL.

\section{REFERENCES}

1. Diamond, L.W., B.N. Nathwani \& H. Rappaport. 1982. Flow cytometry in the diagnosis and classification of malignant lymphoma and leukemia. Cancer 50(6):1122-1135.

2. Diamond, L.W. \& R.C. BRAYLAN. 1980. Flow analysis of DNA content and cell size in non-Hodgkin's lymphoma. Cancer Res. 40(3):703-712.

3. Shackney, S.E., K.S. Skramstad, R.E. Cunningham, D.J. Dugas, T.L. Lincoln \& R.J. LUKEs. 1980. Dual parameter flow cytometry studies in human lymphomas. J. Clin. Invest. 66(6): 1281-1294.

4. Rosenberg, S.A., C.W. Berard, B.W. Brown, JR., et al. 1982. National Cancer Institute sponsored study of classifications of non-Hodgkin's lymphomas: Summary and description of a working formulation for clinical usage. Cancer 49(10):2112-2135.

5. DORFMAN, R.E., J.S. BURKE \& C.W. BERARD. 1981. A new working formulation on nonHodgkin's lymphomas: Background, recommendations, histologic criteria, and relationship to other classifications. In Advances in Malignant Lymphomas. Proceedings of the Third Annual Bristol Meyers Symposium on Cancer Research. Academic Press. New York. N.Y.

6. RAPPAPORT, M. 1966. Tumors of the hematopoietic system. In Atlas of Tumor Pathology. Section 3, Fasc. 8:98-101. Armed Forces Institute of Pathology. Washington, D.C.

7. PalutKe, M., P. Khilanani \& R. Weise. 1976. Immunologic and electron-microscopic characteristics of a case of immunoblastic lymphadenopathy. Am. J. Clin. Pathol. 65(6):929-941.

8. Palutke, M., D.J. Patt, R.W. Weise. C. Varadachari, R. Wylin, C.R. Bishop \& P.M. TABACZKA. 1977. T cell leukemia-Iymphoma in young adults. Am. J. Clin. Pathol. 68(4):429-439.

9. PalutKe, M., L. Eisenberg, J. Kaplan, M. Hussain, K Kuthier, P. Tabaczka, I. MiRChandani \& D. TenEnBaum. 1983. Natural killer and suppressor T cell chronic lymphocytic leukemia. Blood 62(3):627-634.

10. KrishaN, A. 1977. Flow cytometry: Long term storage of propidium iodide/citratestained material. Stain Technol. 52(6):339-343.

11. DEAN, P.N. \& J.H. JETr. 1974. Mathematical analysis of DNA distribution derived from flow cytometry. J. Cell Biol. 60(2):523-527.

12. Lukes, R.J., C.R. Taylor, J.W. Parker, T.L. Lincoln, P.K. Pattengale \& B.H. Tindle. 
1978. A morphologic and immunologic surface marker study of 299 cases of nonHodgkin's lymphomas and related leukemias. Am. J. Pathol. 90(2):461-486.

13. Palutike, M., L. Eisenberg, I. Mirchandan, P. Tabaczka \& M. Hussain. 1982. Malignant lymphoma of small cleaved lymphocytes of the follicular mantle zone. Blood 59(2):317-322.

14. Weisenberger, D.D., H. Kim \& H. RAPPAPORT. 1982. Mantle-zone lymphoma: A follicular variant of intermediate lymphocytic lymphoma. Cancer 49(7):1429-1438.

15. MANN, R.B., E.S. JAFFE \& C.W. BERARD. 1979. Malignant lymphomas-A conceptual understanding of morphologic diversity. Am. J. Pathol. 94(1):105-192.

16. Come, S.E., E.S. JAFFE, J.C. ANDERSEN, R.B. MANN, B.L. Johnson, V.T. DeVtTa JR. \& R.C. YouNG. 1980. Non-Hodgkin's lymphomas in leukemic phase: Clinicopathologic correlations. Am. J. Med. 69(5):667-674. 